\title{
Ethical Decision-Making in Clinical Nutritional Practice
}

\section{François P. R. de Villiers}

Department of Paediatrics and Child Health, School of Medicine, MEDUNSA Campus, University of Limpopo, Pretoria, South Africa. Email: alfafrancois@yahoo.co.uk

Received March 31 ${ }^{\text {st }}, 2011$; revised July $8^{\text {th }}, 2011$; accepted July $15^{\text {th }}, 2011$.

\begin{abstract}
Ethics requires a critical evaluation of assumptions and arguments about norms and values; what should be done and what should not. Practitioners should practice ethically, and the professions should be at the forefront of applied ethics. There are four principles, patient autonomy, beneficence, non-maleficence and justice, which are guides to ethical dayto-day practice. Patient autonomy: autonomy means self-rule by persons of their thoughts and actions. Patient autonomy requires the practitioner to realise that patients have the right to be involved in decision-making on their own behalf. Beneficence refers to the duty of the practitioner to do the best for the patient. The benefits of breast-feeding are many, and the eventual outcome on health enormous. Nevertheless, health-care workers are diffident in promoting breast-feeding, and readily accept excuses for not breast-feeding, contrary to the principle of beneficence. Nonmaleficence refers to the duty of the practitioner not to do harm; it requires the practitioner to withhold harmful therapies; Vitamin E, for example, has been proven to be ineffective as an antioxidant in humans, and large doses have been proven to increase mortality. Yet these are the doses available in supermarkets and "Health shops". Nutritionists should actively advise against harmful "dietary supplementation". Distributive justice requires every patient to have an equal opportunity to obtain appropriate therapy. There are relatively few nutritionists and dieticians in South Africa, and indeed in the entire African continent, but proportionately even fewer in the areas of greatest need. A case illustrates the application of these ethical principles to show how they can be applied to our daily practice. Using these four principles is a practical approach to solving ethical dilemmas.
\end{abstract}

Keywords: Ethics, Patient Autonomy, Beneficence, Non-maleficence, Justic

\section{Introduction}

There is a strong focus on the need for practitioners to practice ethically today. This is not to say that practitioners in the past were unethical or unaware of their obligations to practice ethically. Indeed, some would argue that people acted with more moral rectitude in the past. For many today, there is moral laxity in many sections of society. Maybe that is why there is such a strong focus on the need to formalise the teaching of, the practice of, and continuing education in professional ethics.

Certainly, it is true that if the professions do not regulate themselves, and this includes looking into their moral and ethical obligations, it will be done for them, possibly with deleterious effects. The HPCSA (Health Professions Council of South Africa) has an important role in the regulation of the professions in South Africa. It used to have many professionals taking part in its ac- tivities, and in the formulation of its regulations. However increasingly there are political attempts to reduce the contribution of the professions, and the HPCSA has been loaded with political appointments [1]. Despite this however the professions should from within their own structures proceed with self-regulation. And most assuredly the professions should be at the forefront of applied ethics.

Professional ethics is a branch of Moral Philosophy, or Ethics; the latter is in turn a branch of Philosophy. Philosophy is the pursuit of wisdom by intellectual means, using logical reasoning rather than empirical methods [2]; it is explicitly rational critical thinking of a systematic kind [3]. Ethics therefore entails a critical evaluation of assumptions and arguments about norms and values, good and bad; what should be done and what should not. Concepts which are often confused with Ethics, are explained in Table 1. 
Table 1. What professional ethics is not.

It is not:

The Ethos or Attitudes of the Health-Care Worker Community. These are the "unwritten rules" of a community, a set of principles to which members of a particular group is expected to adhere, at least in the opinion of some members of that community. An alternative (older) meaning is the character, guiding beliefs or fundamental values peculiar to a community (or individual).

A Code of Conduct is a set of (written) conventional principles to which any person who is a member of a particular group is expected to adhere.

A Code of Practice. These are the rules of the profession: a set of rules according to which people in a particular profession are expected to behave; these may be enforced by the profession.

Etiquette in Relation to Health Care Practice. This is the reciprocal interaction of two or more professional individuals [4], and may be included in the Code of Practice.

Medical/Health-Care Law. Law provides boundaries of actions, set by society, beyond which a person risks punishments [5].

\section{Ethical Theories}

There are many ethical systems or theories. Three will be briefly mentioned, namely deontological ethics, utilitarianism, and virtue ethics. Deontological ethics states that it is the duty of a person to act morally correctly. The best-known system of deontological ethics is that of Immanuel Kant. His concept of Respect for Persons is mentioned below. According to utilitarianism, the most morally correct action is that which leads to the biggest utility, or good, or happiness, for the largest number of people. According to virtue ethics, every person should strive to become a virtuous individual by constantly acting virtuously. The actions of such a person then would be morally correct.

In terms of professional (health-care) ethics, four principles are generally held to be helpful guides to help us to act ethically from day-to-day. These are the by now well known principles of patient autonomy, beneficence, nonmaleficence and justice [6].

\section{Patient Autonomy}

It is instructive to learn from the concept of Respect for Persons, which Immanuel Kant espoused in the late $1700 \mathrm{~s}$. Kant stated that persons deserve respect in and of themselves, simply because they have reasoning ability, and they can use this reason to distinguish right from wrong, and to act morally. This faculty means that persons should never be used as a means to an end. Because of their ability to act morally, they should be respected.

Autonomy means self-rule, in other words self-rule by the person of her thoughts, her will, her actions. Patient autonomy requires the practitioner to realise that the patient has the right to be involved in decision-making on her behalf. This is the opposite of therapeutic paternalism (the attitude that the professional knows best). Until recently practitioners thought that they knew better than their patients; patients were frequently informed what the treatment plan was without being involved in the decision-making process.

Examples of patient autonomy include the need to obtain fully informed consent for major therapeutic decisions, especially those for which the evidence of benefit is marginal, as well as consent for operations. However, patient autonomy is also relevant in day-to-day practice when dealing with any treatment plan; the patient's wishes should also be factored into the final decision.

\section{Beneficence}

This refers to the duty of the practitioner to do the best for his/her patient. "Doing my best for the patient" or "It is in the best interests of the patient" are statements which are commonly heard during discussions between health-care workers; these refer to the duty of beneficence. At times one hears statements such as: "The patient's interests always come first". A moment's thinking reveals that this statement can clearly not always be true. There are so many conflicting demands on the health care worker's time, and indeed, demands from several patients, that one can clearly see that the patient's interests are often in conflict with other patients interests, as well as other requirements for the health-care worker's attention. The sentiment expressed by this statement has been called "Unthinking Absolutism" [7].

Nevertheless it is clear that society thinks that doctors have a duty of beneficence their patients, as well as to members of society. This is well illustrated, when in a theatre or an aeroplane, a doctor's help is called for over the loudspeaker system for some unfortunate spectator or passenger who is in medical difficulty [7]. This duty of beneficence towards society is also expanded to include other health-care workers.

The duty of beneficence is not always absolute as we have seen above. It has to be balanced with the other three principles. For example, the patient may not always want that which is best for him/her, in which case the principle of patient autonomy has to be balanced with beneficence. At times doing the best for the patient may require therapy with unpleasant or even even harmful side-effects, in which case the duty not to do harm needs to be considered. Justice may require that the good of one or some patient(s) will take precedence over the good of other patients.

An example of the application of beneficence is the following. Breast-feeding is well known to be much bet- 
ter than bottle feeding for infants. The benefits of breastfeeding are many, and the eventual beneficial outcome on health is enormous. In the Third World, breast-feeding is life-saving (even allowing for the effect of HIV/ AIDS). Infants who are not breast-fed in developing countries, are six to 10 times more likely to die in the first months of life [8].

Even in the developed world, breast-feeding is much more beneficial than bottle feeding, if the few medical contraindications to breast-feeding (galactosaemia, maple syrup urine disease, phenylketonuria) [9] are excluded. HIV infection is a maternal condition that may justify permanent avoidance of breastfeeding, but only if replacement feeding is acceptable, feasible, affordable, sustainable and safe (AFASS) [9].

To return to the benefits of breast-feeding, or rather the negative consequences of not breast-feeding: not breast-feeding a baby will cause that infant to fall prey to between two and five times more attacks of acute otitis media, to 1.5 times more respiratory illnesses and 1.7 to 2 times more gastro-intestinal infections [10,11]. Furthermore that infant's chances of developing allergic eczema (atopic dermatitis) will increase by 1.7 times, her chance of developing asthma also by 1.7 times, [11] all allergy related problems by 1.3 to 1.9 times, [10,11] and becoming overweight or obese will be reduced by $4 \%$ for every month of breast-feeding [11]. Further benefits have been described with regard to the number of hospitalisations, the rate of sudden infant death syndrome, the prevalence of childhood cancers, type 1 diabetes mellitus, and meningitis [10]. As adults, persons who were not breast-fed during infancy have higher cholesterol levels, higher risk for heart disease, and higher blood pressures [10]. This list is not comprehensive, and does not even include benefits for the mother, reductions in medical costs, and other economic benefits to the family.

Comparing the benefits of breast-feeding with drug therapy, the example of acute otitis media is used: as stated above, a baby who is not breast-fed will suffer between two and five times more attacks than a breasted baby. When children with acute otitis media are treated with antibiotics, 30\% will still have pain or fever after three to seven days, compared with $55 \%$, were not treated. The rate difference is $25 \%$, i.e. antibiotics are only more effective than no treatment in one quarter of the cases [12]. Yet the vast majority of mothers who will not breast-feed, will insist on antibiotics in this situation.

If any drug were as effective as breast-feeding in preventing a myriad of conditions, its use would be promoted by lay people and professional bodies alike; its benefits would be shouted from the rooftops, in magazines and on television. It would be considered negligent on the part of health-care workers if they did not prescribe it. According to the principle of beneficence, breastfeeding should therefore be prescribed to all pregnant women by all the health-care workers whom they consult. In a recent policy statement, The United States Preventive Services Task Force notes that "there is convincing evidence that breast-feeding provides substantial health benefits for children and adequate evidence that breastfeeding provides moderate health benefits for women". They proceed to recommend "interventions in pregnancy and after birth to promote and support breast-feeding. [13]

Why then is breast-feeding not encouraged on a much wider scale, and much more vociferously? Why are health-care workers so diffident in promoting breastfeeding? Why do health-care workers readily accept any flimsy excuse why a mother should not breast-feed? This is an extremely serious ethical problem which the professsion needs to grapple with.

\section{Non-maleficence}

This is, as it were, the other side of the coin of beneficence; it refers to the duty of the practitioner not to do harm. The Latin expression "Primum non nocere", which means "firstly, not to do harm", is a reflection of this duty. Taken on its own, non-maleficence can lead to therapeutic nihilism, i.e., the attitude that, in order to avoid any harm, it is better to do nothing. This is indefensible. It can be seen that these two principles (beneficence and non-maleficence) require us to balance the risks and benefits; and to consider the need to avoid doing harm, against the duty to do good.

The principle of non-maleficence requires the practitioner to withhold harmful therapies or medications; vitamin $\mathrm{E}$ will be used as an example in this regard.

Vitamin $\mathrm{E}$ has been used as an anti-oxidant in clinical practice for many years. Tocopherols act as free radical scavengers when they encounter free radicals. For example, when $\alpha$-tocopherol (Vitamin E) encounters a lipid radical (a lipid with an oxygen radical attached), vitamin E donates a hydroxy group $\left(\mathrm{OH}^{-}\right)$in exchange for the oxygen radical. The resulting tocopherol radical is relatively stable, and is reduced back to vitamin $\mathrm{E}$ by NADPH reductase and ascorbate [14]. The idea that vitamin E could in humans act as an antioxidant, with the intention to prevent chronic diseases, and therefore mortality [15], is certainly biologically plausible. However, this idea has not been proven to be effective in randomised controlled trials, some of which have been published as long ago as 1994. Three meta-analyses, published in 2003 and 2004, showed no evidence that vitamin E was beneficial in reducing mortality [16-18] .

Meanwhile, some trials of high-dose vitamin E sup- 
plementation, have reported increases in total mortality (statistically not significant). Huge doses of vitamin E $(\geq 400 \mathrm{Iu} /$ day) were subsequently proven to increase mortality in an extremely large meta-analysis, including 135967 participants of whom 40950 received dosages of $400 \mathrm{Iu} /$ day or more [15]. A more recent, even bigger meta- analysis confirmed these findings [19].

In South Africa, in combined supplements, containing several or many ingredients, the dosages of vitamin $\mathrm{E}$ are usually much less than $400 \mathrm{Iu}$, but most exceed the RDA severalfold: it is rare to find a supplement in which the RDA is less than $100 \%$. This does not even take into account the fact that there are still claims that the current RDA is double that which healthy people consume, and therefore at least $50 \%$ too high [20]. However, vitamin E as a single supplement is available in dosages of $400 \mathrm{Iu}$ or more; it is virtually impossible to get vitamin $\mathrm{E}$ alone in a capsule at a lower dose. These killer doses are available in Supermarkets, Pharmacies and "Health shops". These problems are summarised in Table 2.

What must the Nutrition Practitioner do? Avoid harm. It is absolutely essential that nutritionists and dieticians be heard to actively advise against "dietary supplementation" which is harmful.

\section{Justice}

Several forms of justice exist: retributive justice means retribution or pay-back, i.e., the guilty party is punished; restorative justice means making reparation to victims; and distributive justice means that everyone should have equal access (to goods, health care etc) or at least equal opportunities.

Justice, as one of the four principles, means equity or distributive justice; every patient should have an equal opportunity to obtain appropriate therapy [6]. Competing claims exist everywhere; in a country with limited resources, with a wide disparity of income between the lower income and the upper income groups, with a vast pre-dominance of the population having to use public hospitals, and with a rural population without access to health services, this principle is frequently problematic.

There are relatively few nutritionists and dieticians in Africa, but proportionately even fewer in the areas of greatest need. As is the case with other healthcare pro-

Table 2. The problem of vitamin $\mathrm{E}$.

Vitamin E as Anti-oxidant.
Proven not to be effective in humans
Huge doses ( $\geq 400 \mathrm{Iu} /$ day) proven to increase mortality
Yet these are the doses available in Supermarkets, Pharmacies and
"Health shops"

fessionals, nutritionists are concentrated in cities and in private practice. There is a definite need for nutritionists to be involved in the food service in hospital kitchens (and in large kitchens of other institutions), and of course, to design specific meal plans for individual patients. There is clearly also a need for nutritional professionals to work in country settings rather than only in the cities. When one works in a private practice or a private hospital, there is more time to design complicated, patientspecific diets, rather than simply concentrate on the basic needs; however both these approaches are necessary. An individual practitioner might consider donating some time (rather than just money) to charity, for example by helping with the meal plans for an old age home. Questions the Profession needs to debate are shown in Table 3.

\section{Truth-Telling}

This is not an independent principle, but is a logical conclusion flowing from the principles of Patient autonomy and of Beneficence. A patient cannot make autonomous decisions if health-care workers do not do tell the truth, and generally telling the truth will do more good than not doing so.

Some arguments against truth-telling are the following: firstly, telling unpleasant truths about the patient's medical condition or prognosis may undermine the patient's morale or the efficacy of the placebo effect. This means that the principle of beneficence, as well as the principle of nonmaleficence are being violated in this instance of truth-telling. This argument may occasionally be true, but generally this is just paternalism (the attitude that the professional knows best) dressed up in sophisticated terms [7].

A second argument is, that truth cannot be communicated, because the health-care worker cannot know the truth in its entirety, and furthermore the patient is not able to understand it [7]. Two different arguments are being offered here; as to not knowing the whole truth, it is of course true that no person is all-knowing. However that is not an effective argument, as the health-care worker is not functioning with absolute knowledge, but rather with knowledge as it is accepted by the profession

Table 3. Justice in nutrition.

\footnotetext{
To practically apply the principle of justice

Why so few Nutritionists in Africa?

Why so few Nutritionists where it really matters: with the poor and the extremely ill?

These are questions the Profession needs to debate, plan for, and actively address.
} 
at the time, and this is what is to be communicated to the patient. Concerning the patient's ability to understand, it is also true that the patient does not have the training of the health-care worker. Furthermore the intellectual capacity of different patients differ. None of this however interferes with the obligation of health-care worker to tell the complete truth to the patient in so far as it is accepted by the profession at that time, keeping in mind her capacity to understand. The inability of the health-care worker to make herself understandable, i.e. not fall back into medical jargon, is maybe one of the reasons for health-care workers' unease concerning this. Increasing stress is being laid on communication in the training of health-care workers; the onus is therefore on the professsional to learn to communicate appropriately with patients.

A further argument against truth-telling is that patients do not want to know the truth [7]. Although there is evidence that this is occasionally true, in that a small proportion of patients, especially those with a terminal disease and a poor prognosis, prefer minimal information, and no active role in decision-making [21-22], research shows that this statement is false in more than $80 \%$ of the cases [23-24].

\section{Case Study}

The four principles will now be applied to the following case study:

Mr W. B. is a 45-year-old Afrikaans male. He is married, and the couple has three teenage children. He is an Artisan who works as a foreman for a building contractor.

Dr. P. (a general practitioner) had referred him to Dr. N (a Physician) for his "chronic indigestion". In turn, Dr. $\mathrm{N}$ referred him to you, a dietician, with the information that his father had died at 38 years of age from a "heart attack". Dr. N also noted that Mr W. B. is obese, with the abdominal type obesity, and asks you to "put Mr W. B. on a diet".

You confirm the abdominal obesity and a BMI of 31 with the appropriate measurements. Mr W. B.'s dietary intake is shown in Table 4.

You have to work out an appropriate meal plan.

Not really very challenging, indeed fairly standard: a weight reduction, healthy, balanced diet.

If we apply the principles of ethics to this case, we can argue as follows:

Justice: this principle does not really apply to this case.

Beneficence: Your meal plan will do $\mathrm{Mr}$ W. B. a world of good (or will it?)

Non-maleficence: Do not do harm. Well your meal plan will not do Mr W. B. any harm, will it?

Patient autonomy: How much autonomy do you allow
Table 4. Mr W. B.’s daily bread.

According to Mr W. B., he eats the following:
Breakfast:
"No time for breakfast"
Rusks and coffee
Lunch:
Four white bread sandwiches
Recently: salad and fruit
Dinner:
Red meat and three vegetables. Actually, potatoes, rice, and
sweetened carrots or pumpkin (i.e. 3 high carbohydrate foods)
Beverages:
"Coke" (Coca-Cola) at work
Beer, or brandy and "Coke" at other times.

the patient in your meal plan?

He really doesn't want to change, but he is very polite and agrees with everything you say.

So, what does Mr W. B.'s case teach us?

You drew up a technically perfect healthy, balanced, weight reduction diet. Is this the ethical thing to do? Considering $\mathrm{Mr} \mathrm{W}$. B's preference for red meat and refined carbohydrates, is it realistic to think that he himself eats his lunchbox food (the salad and fruit that his caring wife so diligently packs)? Is it realistic to expect him to change his food intake so drastically? We know that many people refer to such a meal plan as "rabbit food" or "food for sissies".

It is quite likely to be possible to negotiate a much less drastic change to his diet which will be more likely to be sustainable for him, while allowing him to retain a certain amount of his self-respect. Although such therapy will take much longer to be effective (in ideal conditions), it has the benefit of better patient adherence. And, of course, you will have acted respecting Mr W. B.'s autonomy.

\section{Conclusions}

Ethical decision-making in clinical practice does not only affect life and death issues (e.g. abortion and euthanasia), or morally complex issues (e.g. truth telling to a cancer patient), but can also be applied in our daily practice as illustrated by the case study above.

Using the four principles popularised by Beauchamp and Childress [6] is an easy and practical approach to solving ethical dilemmas.

\section{REFERENCES}

[1] J. P. de V. Van Niekerk, "HPCSA: A Mess in the Health Department's Pocket," South African Medical Journal, Vol. 99, No. 4, 2009, p. 203

[2] Anonymity, "The American Heritage Dictionary," 4th 
Edition, Dell, New York, 2001.

[3] T. Honderich, Ed., "The Oxford Companion to Philosophy (2nd Edition)," Oxford University Press, New York, 2005.

[4] Anonymity, "Medical Dictionary Online," 2009. http://www.online-medical-dictionary.org/accessed19Aug 2009

[5] Anonymity, "Relationship of Law and Ethics," 2009. http://www.britannica.com/accessed19Aug2009

[6] T. L. Beauchamp and J. F. Childress, "Principles of Biomedical Ethics," 5th Edition, Oxford University Press, New York, 2001.

[7] R. Gillon, "Philosophical Medical Ethics," Wiley, New York, 1992.

[8] World Health Organization, "Infant and Young Child Feeding: Model Chapter for Textbooks for Medical Students and Allied Health Professionals," WHO Press, Geneva, 2009.

[9] World Health Organization/UNICEF, "Acceptable Medical Reasons for Use of Breast-Milk Substitutes," WHO Press, Geneva, 2009.

[10] E. Evenhouse and S. Reilly, "Improved Estimates of the Benefits of Breast-Feeding Using Sibling Comparisons to Reduce Selection Bias," Health Services Research, Vol. 40, No. 6, 2005, pp. 1781-1789. doi:10.1111/j.1475-6773.2005.00453.x

[11] M. Chung, G. Raman, T. Trikalinos, J. Lau and S. Ip, "Interventions in Primary Care to Promote Breast-Feeding: An Evidence Review for the US Preventive Services Task Force," Annals of Internal Medicine, Vol. 149, No. 8, 2008, pp. 565-582.

[12] M. M. Rovers, P. Glasziou and C. L. Appelman, "Antibiotics for Acute Otitis Media: A Meta-analysis with Individual Patient Data," The Lancet, Vol. 368, No. 9645, 2006, pp. 1429-1435. doi:10.1016/S0140-6736(06)69606-2

[13] US Preventive Services Task Force, "Primary Care Interventions to Promote Breast-Feeding: US Preventive Services Task Force Recommendation Statement," Annals of Internal Medicine, Vol. 149, No. 8, 2008, pp. 560-564.

[14] K. Hensley, E. J. Benaksas, R. Bolli, P. Comp, P. Grammas, L. Hamdheydari, S. Mou, Q. N. Pye, M. F. Stoddard, G. Wallis, K. S. Williamson, M. West, W. J. Wechter and R. A. Floyd, "New Perspectives on Vitamin E: $\gamma$-Tocopherol and Carboxyhydroxychroman Metabolites in Biology and Medicine," Free Radical Biology and Medicine, Vol. 36, No. 1, 2004, pp. 1-15. doi:10.1016/j.freeradbiomed.2003.10.009

[15] E. R. Miller, R. Pastor-Barriuso, D. Dalal, R. A. Riemersma, L. J. Appel and E. Guallar, "Meta-analysis: High-
Dosage Vitamin E Supplementation May Increase AllCause Mortality," Annals of Internal Medicine, Vol. 142, No. 1, 2005, pp. 37-46.

[16] R. S. Eidelman, D. Hollar, P. R. Hebert, G. A. Lamas and C. H. Hennekens, "Randomized Trials of Vitamin E in the Treatment and Prevention of Cardiovascular Disease," Archives of Internal Medicine, Vol. 164, No. 14, 2004, pp. 1552-1556. doi:10.1001/archinte.164.14.1552

[17] P. G. Shekelle, S. C. Morton and L. K. Jungvig, "Effect of Supplemental Vitamin E for the Prevention and Treatment of Cardiovascular Disease," Journal of General Internal Medicine, Vol. 19, No. 4, 2004, pp. 380-389. doi:10.1111/j.1525-1497.2004.30090.x

[18] D. P. Vivekananthan, M. S. Penn, S. K. Sapp, A. Hsu and E. J. Topol, "Use of Antioxidant Vitamins for the Prevention of Cardiovascular Disease: Meta-analysis of Randomized Trials," The Lancet, Vol. 361, No. 9374, 2003, pp. 2017-2023. doi:10.1016/S0140-6736(03)13637-9

[19] G. Bjelakovic, D. Nikolova and L. L. Gluud, "Mortality in Randomized Trials of Antioxidant Supplements for Primary and Secondary Prevention: Systematic Review and Meta-analysis," Journal of the American Medical Association, Vol. 297, No. 8, 2007, pp. 842-857. doi:10.1001/jama.297.8.842

[20] M. K. Horwitt, "Critique of the Requirement for Vitamin E," American Journal of Clinical Nutrition, Vol. 73, No. 6, 2001, pp. 1003-1005.

[21] P. Butow, R. Devine, M. Boyer, S. Pendlebury, M. Jackson and M. H. N. Tattersall, "Cancer Consultation Preparation Package: Changing Patients but Not Physicians is Not Enough," Journal of Clinical Oncology, Vol. 22, No. 21, 2004, pp. 4401-4409. doi: $10.1200 / \mathrm{JCO} .2004 .66 .155$

[22] M. Gattellari, K. J. Voigt, P. N. Butow and M. H. N. Tattersall, "When the Treatment Goal is Not Cure: Are Cancer Patients Equipped to Make Informed Decisions?" Journal of Clinical Oncology, Vol. 20, No. 2, 2002, pp. 503-513. doi:10.1200/JCO.20.2.503

[23] P. Kinnersley, A. Edwards and K. Hood, "Interventions before Consultations to Help Patients Address Their Information Needs by Encouraging Question Asking: Systematic Review," British Medical Journal, Vol. 337, No. 3, 2008, p. a485. doi:10.1136/bmj.a485

[24] M. Levetown and the Committee on Bioethics, "Communicating with Children and Families: From Everyday Interactions to Skill in Conveying Distressing Information," Pediatrics, Vol. 121, No. 5, 2008, pp. e1441-e1460. doi:10.1542/peds.2008-0565 